Document downloaded from:

http://hdl.handle.net/10251/163175

This paper must be cited as:

Herrera, RF.; Mourgues, C.; Alarcón, LF.; Pellicer, E. (2021). Analyzing the Association between Lean Design Management Practices and BIM Uses in the Design of Construction Projects. Journal of Construction Engineering and Management. 147(4):1-11. https://doi.org/10.1061/(ASCE)CO.1943-7862.0002014

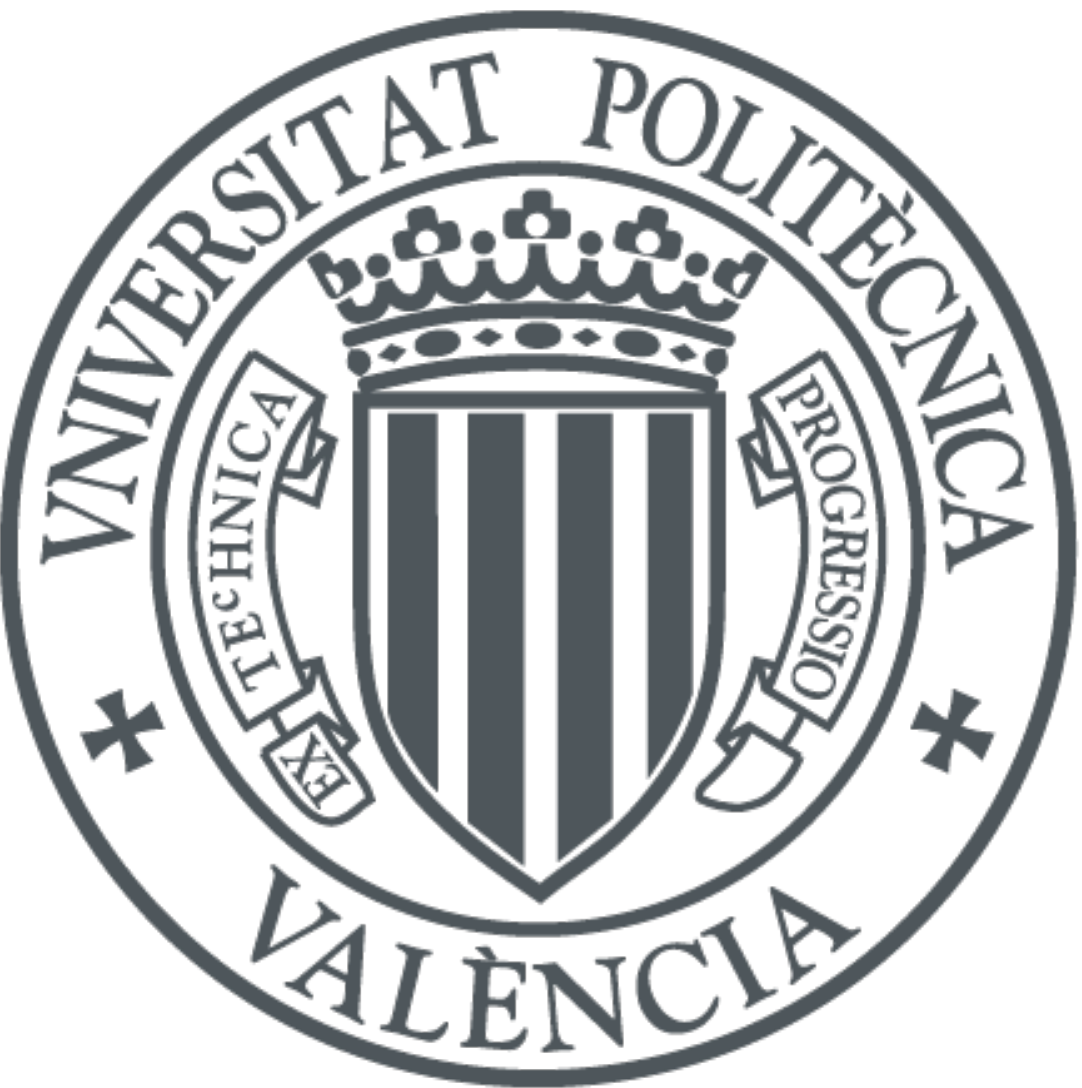

The final publication is available at

https://doi.org/10.1061/(ASCE)CO.1943-7862.0002014

Copyright American Society of Civil Engineers

Additional Information 


\section{ANALYZING THE ASSOCIATION BETWEEN LEAN DESIGN \\ MANAGEMENT PRACTICES AND BIM USES IN THE DESIGN \\ OF CONSTRUCTION PROJECTS}

\section{Introduction}

Building Information Modeling (BIM) per (Eastman et al. 2008, p.491) is "a new approach to design, construction, and facilities management, in which a digital representation of the building process [is used] to facilitate the exchange and interoperability of information in digital format". For this reason, BIM has been related to the development of lean approaches to project management, as improved collaboration and information exchange can contribute to the lean management goal of reducing waste (Olatunji 2011). There is a strong synergy between lean construction and BIM (Eastman et al. 2011), which has been documented in many case studies where it is possible to visualize the interaction between both methodologies (Sacks et al. 2010). The interactions between BIM and Lean are mutual, i.e. the development of BIM contributes to the development of Lean, and also the development of Lean contributes to the development of BIM (Nascimento et al. 2018; Sacks et al. 2010). In particular, BIM has a high technological component that has been extensively studied in recent years; however, its implementation has several challenges from the perspective of people and organizational processes (Arayici et al. 2011). For instance, BIM requires profound process changes of the involved parties, and a higher team communication (Fakhimi et al. 2016).

On the other hand, the foundation of Lean construction is based on the theory of production (Koskela 2000), and it is people- and process-focused. Therefore, BIM with its technology capability and Lean with its theoretical foundation can complement each other for better project efficiency (Al Hattab and Hamzeh 2015). Sacks et al. (2010) presented 56 distinct interactions between lean construction principles and BIM 
functionalities, which were grouped in a Lean/BIM matrix. This study initiated extensive research into the synergies between Lean and BIM in the architecture, engineering and construction industry (AEC), being cited in more than 500 scientific papers, and it is also a foundation for the research introduced in this paper.

BIM in fact will become increasingly essential and an inextricably linked component to a Lean construction process, especially within the context of abundant geometric and semantic project information (Schimanski et al. 2019). For example, Schimanski et al. (2019) describe three practical case studies through BIM-based objectives and outcomes and map these outcomes to the taxonomy of interactions described by Sacks et al. (2010). All three case studies have demonstrated advances in the core tenet of delivering increased value to clients while significantly reducing waste in the form of time, material, and financing. In these examples, the implementation was primarily BIM-based methods, and secondarily, incremental inclusion of Lean definitions. Based on the synergies of BIM and Lean, specific tool applications have been developed, such as the Digital Obeya Room framework (Nascimento et al. 2018); "VisiLean", which uses BIM as the visual platform and enables pull flow scheduling on the construction site (Dave 2013); "BeaM!", which allows a joint application of BIM and the Last Planner ${ }^{\circledR}$ System (LPS) (Schimanski et al. 2019); and "KanBIM", which mixes Kanban and BIM (Sacks et al. 2011). A Lean tool can be defined as an structured technique or instrument that facilitates the implementation of the Lean principles (O'Connor and Swain 2013), such as, the last planner system, 5S, big rooms, and collaborative process mapping, among others. On the other hand, a management practice refers to concrete actions associated with increasing productivity (Bloom and Van Reenen 2007), such as, specialist designers and builders involvement during early stages of the project, the systematic participation or support of 
the clients, and the collaborative planning among various stakeholders, among others (Herrera et al. 2020).

In addition, some authors have indicated that lean practices can enable BIM adoption (Gerber et al. 2010). For instance, Arayici et al. (2011) have used lean-inspired action research interventions to enhance the adoption of BIM in an architectural company, from which the researchers developed detailed, operational-level guidelines to be used during implementations in this type of organization. Gerber et al. (2010) present qualitative evidence that indicates using lean and BIM in conjunction with each other can significantly improve BIM adoption and, consequently, project performance in India and perhaps elsewhere. Therefore, some lean practices reduce coordination-related issues within the project organization, paving the way for BIM adoption (Magalingam et al. 2015). By understanding the benefits of BIM and lean interactions, the design errors can be handled better in an attempt to reduce both their incidence and their dissemination (Magalingam et al. 2015). Some of the benefits of using an integrated BIM and Lean approach in the design stage of construction were summarized by Dave et al. (2013): reducing the design development lifecycle, reducing rework, increasing the number of iterations for value improvement, improving predictability of investment and lifecycle costs (4D scheduling), and enhancing the ability to engage with stakeholders. However, applying BIM alone as a technology and failing to employ it as a lean process does not bring about the desired benefits dissemination (Magalingam et al. 2015). To realize the full potential benefit of BIM and Lean methods, both need to be used collaboratively in a project (Fakhimi et al. 2016). However, both methodologies have been studied in depth on their own, and contributions about their synergies are quite recent; hence, the available assessment instruments used to measure the level of implementation of both methods so far are unrelated (Peralta 2019). For example, on the one hand, there are many uses of 
BIM reported by various authors (Bloomberg et al. 2012; Building and Construction Authority 2013; Harvard University Construction Management Council 2010; Succar 2016), which can be implemented during the project life cycle (Kreider and Messner 2013); therefore, a BIM use is a set of actions and conditions that are associated with BIM, which together have a defined objective or application for the construction project during its life cycle (Rojas et al. 2019). On the other hand, there are also many Lean practices and tools that can be applied from design to project demolition (Ballard 2008; Forbes and Ahmed 2011). However, Lean practices applied to BIM uses (defined in the BIM execution plan) are not known up to now.

An unexplored perspective on these synergies concerns the relationship between the specific uses of BIM and Lean practices. While some of this can be seen in the matrix proposed by Sacks et al. (2010), this study is limited to an analysis of the literature focused on Lean principles, not practices. Additionally, there are empirical studies that provide evidence of the potential of the application of BIM and Lean (Gerber et al. 2010; Matta et al. 2018; Schimanski et al. 2019); however, these are limited to the application of particular Lean tools and BIM uses in a limited number of case studies. Hence, a comprehensive understanding of BIM/Lean management is needed. Also, there are instruments to assess the gradualness of implementation of lean practices and BIM uses on their own, but there are no experiences that present the joint evaluation of both methodologies.

This is particularly important in the design phase of construction projects because the decisions made during this phase can significantly affect the subsequent phase, and the costs of changes in the design phase are negligible compared to the costs of changes in future phases (AIA 2007). Then, particularly the Lean design management (LDM) practices are processes or methods related to Lean philosophy that are usually applied in 
the design phase of a construction project. Herrera et al. (2020) developed an instrument to assess 19 LDM practices; however, this instrument has not yet been compared to BIM uses applied in early project phases. Furthermore, Rojas et al. (2019) designed a instrument to assess ten BIM uses during the planning and design of construction projects; nevertheless, this instrument has not yet been compared to the Lean management practices implemented on those projects. Thus, there is no empirical evidence of the relationship between BIM uses and LDM practices. Additionally, there is also no evidence of causality between Lean and BIM, i.e., it is not known whether companies with high levels of Lean implementation are using BIM extensively or whether projects using BIM are applying Lean practices on actual projects.

Therefore, the purpose of this study is to analyze the relationships between Lean Design Management (LDM) practices and the uses of BIM in the early stages of construction projects, i.e., during the planning and design phases. The analysis of the relationship between LDM practices and BIM uses will allow having empirical evidence of the LDM practices that are present in each BIM use in the design phase of construction projects. To achieve this, the LDM practices and the BIM uses is explained in the Background section. Then, in the Research Method section, the relationship analysis is explained in depth. Finally, in the Results and Discussion section, the assessing of the LDM practices and BIM uses of 64 construction projects in the design phase are discussed.

\section{Background}

\section{$\underline{\text { Lean Design Management (LDM) practices }}$}

Lean design introduces several elements that are part of the Lean philosophy and that are fundamental in the design phase, for example, the active and systematic involvement of clients during early stages, maximization of value, identification of the needs and 
objectives of all interested parties, simultaneous realization of the design of the product and the process, and postponement of the decision-making step until the last responsible moment, with the aim of reducing reworks and unnecessary tasks (Gambatese et al. 2017). Better management practices are significantly associated with higher productivity, profitability, sales growth rates and firm survival rates (Bloom and Van Reenen 2007). Therefore, the Lean design management (LDM) practices will be the best management practices according to Lean philosophy, which will allow having a better performance in the design phase of a construction project. While Lean has been applied in the design phase of construction projects for more than 20 years (Formoso et al. 1998; Koskela et al. 1997), recently a framework has been proposed that integrates LDM practices and that allows an assessment of the level of implementation of each practice on a scale of 1 to 5 (Herrera et al. 2020).

Lean implementation in the design phase could be applied through multiple tools (e.g., set-based design, choosing by advantages, target value design, the last planner system, or big room), which could include one or several LDM practices. However, this research did not study particular tools because it was determined to have a comprehensive approach to Lean design management though LDM practices. Herrera et al. (2020) proposed 19 LDM practices in the design phase of construction projects. These practices were classified into three main categories: stakeholder management, planning and control, and problem solving and decision making. These authors proposed a questionnaire to assess the degree of implementation of each of the practices at the project level, defining a taxonomy of LDM practices in a scale of five levels (Herrera et al. 2020). The present research used this questionnaire to assess LDM practices. Table 1 presents a definition of these 19 LDM practices.

Table 1: Lean design management (LDM) practices (Herrera et al. 2020) 


\begin{tabular}{|c|c|}
\hline ID & Definition \\
\hline \multicolumn{2}{|c|}{ STAKEHOLDER MANAGEMENT } \\
\hline SM1 & Specialist designers are involved during early stages of the project. \\
\hline $\mathbf{S M}_{2}$ & Builders are involved during early stages of the project. \\
\hline $\mathbf{S M}_{3}$ & $\begin{array}{l}\text { The identification of requirements of the stakeholders is exhaustive, where } \\
\text { requirements, constraints, technical specifications and special requirements are } \\
\text { defined. }\end{array}$ \\
\hline $\mathrm{SM}_{4}$ & $\begin{array}{l}\text { The participation of clients in the design phase involves the systematic } \\
\text { participation and support during meetings concerning decision making and } \\
\text { resolution of problems. }\end{array}$ \\
\hline SM5 & $\begin{array}{l}\text { The design of the product and the construction process are carried out } \\
\text { simultaneously. }\end{array}$ \\
\hline \multicolumn{2}{|c|}{ PLANNING AND CONTROL } \\
\hline $\mathbf{P C}_{1}$ & $\begin{array}{l}\text { Project planning considers delivery dates, phases, milestones, task subdivision } \\
\text { programs and control instances. All of the above, immersed in a scheme in } \\
\text { which gaps, buffers and points are clarified, can be used to perform pull/push } \\
\text { actions within the program. }\end{array}$ \\
\hline $\mathrm{PC}_{2}$ & $\begin{array}{l}\text { With regard to project planning, this is considered information of internal } \\
\text { and/or external projects of the organization, generated through a } \\
\text { benchmarking exercise. }\end{array}$ \\
\hline $\mathbf{P C}_{3}$ & Project planning is conducted collaboratively among various stakeholders. \\
\hline $\mathrm{PC}_{4}$ & $\begin{array}{l}\text { Project planning is carried out at different levels (global, phase, intermediate } \\
\text { and weekly). }\end{array}$ \\
\hline $\mathrm{PC}_{5}$ & $\begin{array}{l}\text { The constraints in the design process are identified and registered } \\
\text { collaboratively and released by a responsible person. Then, the constraints are } \\
\text { followed. }\end{array}$ \\
\hline $\mathbf{P C}_{6}$ & $\begin{array}{l}\text { The coordination of project information between the different stakeholders is } \\
\text { performed through a single platform, which allows systematic updates and } \\
\text { continuous communication between stakeholders. }\end{array}$ \\
\hline \multicolumn{2}{|c|}{ DECISION MAKING } \\
\hline $\mathbf{D M}_{1}$ & There exists a protocol to solve problems collaboratively. \\
\hline $\mathbf{D M}_{2}$ & $\begin{array}{l}\text { The last planner identifies the problem and performs a causal analysis (e.g., } \\
\text { the } 5 \text { why's method). }\end{array}$ \\
\hline $\mathbf{D M}_{3}$ & $\begin{array}{l}\text { The solution to the problem is implemented, monitored and documented, to } \\
\text { verify that the problem was solved. }\end{array}$ \\
\hline $\mathbf{D M}_{4}$ & $\begin{array}{l}\text { In the decision-making process, options are evaluated, designed, and tested, } \\
\text { and the results validated and applied. }\end{array}$ \\
\hline DM5 & $\begin{array}{l}\text { The moment to make decisions is the last responsible moment, and all the } \\
\text { information that could be gathered at that moment is used. }\end{array}$ \\
\hline DM6 & $\begin{array}{l}\text { To make decisions, information of internal and/or external projects of the } \\
\text { organization is used, generated through a benchmarking exercise. }\end{array}$ \\
\hline $\mathbf{D M}_{7}$ & $\begin{array}{l}\text { The decision-making mechanism is a meeting with all stakeholders involved, } \\
\text { where a specific technique is used, for example, Choosing By Advantages } \\
\text { (CBA) or others. }\end{array}$ \\
\hline DMs & $\begin{array}{l}\text { After making the decision, specific actions are taken to verify whether } \\
\text { satisfactory results were obtained. In addition, the lessons learned are } \\
\text { identified and documented. }\end{array}$ \\
\hline
\end{tabular}




\section{BIM uses in the planning and design phase}

BIM use is defined as "a method of applying building information modeling during a facility's lifecycle to achieve one or more specific objectives" (Kreider and Messner 2013, p. 6). BIM maturity models could be used to measure the level of application of BIM in a project. However, they allow the assessment of BIM capability and BIM status in an organization (Succar et al. 2012), but not specifically the application of BIM uses. Additionally, there are several guidelines that define BIM uses in the project life cycle (Bloomberg et al. 2012; Building and Construction Authority 2013; Harvard University Construction Management Council 2010), Penn State's guide being the one that stands out for its high level of theoretical and empirical support (Kreider and Messner 2013). Originally, these guidelines did not propose a scale of gradual implementation of each BIM use; however, Rojas et al. (2019) recently proposed an instrument to diagnose some of the BIM uses proposed in the Penn State guidelines (Kreider and Messner 2013). Rojas et al. (2019) designed a BIM uses assessment (BUA) instrument, which allows companies and clients to identify the status of BIM uses of the project, the way that BIM uses are being implemented, and the design team's opportunities for improvement. With this approach, it is possible to realize higher benefits from the BIM methodologies when they are applied in the earliest stages of the projects (planning and design). Table 2 presents a definition of the ten BIM uses for the planning and design of construction projects considered in this study.

Table 2: BIM uses for the planning and design of construction projects (Rojas et al.

2019)

\begin{tabular}{|l|l|l|}
\hline ID & Use & Definition \\
\hline $\mathbf{U}_{1}$ & Cost Estimation & $\begin{array}{l}\text { A BIM model is used to generate accurate quantity take-offs } \\
\text { and cost estimates. }\end{array}$ \\
\hline $\mathbf{U}_{2}$ & 4D Planning & $\begin{array}{l}\text { A 4D BIM model is utilized to effectively plan, especially } \\
\text { spatial planning, including spatial clashes and paths. }\end{array}$ \\
\hline
\end{tabular}




\begin{tabular}{|c|c|c|}
\hline ID & Use & Definition \\
\hline $\mathbf{U}_{3}$ & Site Analysis & $\begin{array}{l}\text { BIM/GIS is used to select and evaluate a site location and to } \\
\text { select a building position on the site. }\end{array}$ \\
\hline $\mathbf{U}_{4}$ & $\begin{array}{l}\text { Space } \\
\text { Programming }\end{array}$ & $\begin{array}{l}\text { A BIM model is used to design and analyze the project spaces } \\
\text { and rooms and to assign to each space a use and its } \\
\text { measurements. }\end{array}$ \\
\hline $\mathbf{U}_{5}$ & Design Review & $\begin{array}{l}\text { A process in which stakeholders interact with a BIM model } \\
\text { and provide their feedback to validate multiple design aspects }\end{array}$ \\
\hline $\mathbf{U}_{6}$ & Code Validation & $\begin{array}{l}\text { A process in which code validation software is utilized to } \\
\text { check the model parameters against project-specific design } \\
\text { or construction codes or norms. }\end{array}$ \\
\hline $\mathbf{U}_{7}$ & $\begin{array}{l}\text { Sustainability } \\
\text { Evaluation }\end{array}$ & $\begin{array}{l}\text { A process in which the sustainability of a facility is evaluated } \\
\text { and tracked using a sustainability metric system. }\end{array}$ \\
\hline $\mathbf{U}_{8}$ & $\begin{array}{l}\text { Engineering } \\
\text { Analysis }\end{array}$ & $\begin{array}{l}\text { A BIM model and specialized software are used to conduct } \\
\text { an engineering analysis to identify the most efficient method } \\
\text { or design. }\end{array}$ \\
\hline U9 & $\begin{array}{l}\text { Design } \\
\text { Authoring }\end{array}$ & $\begin{array}{l}\text { A process in which } 3 \mathrm{D} \text { software is used to develop a building } \\
\text { information model. A project is designed in a BIM model, } \\
\text { where the typical iterations of a project are made, and } \\
\text { everything is built directly in the BIM software. }\end{array}$ \\
\hline $\mathbf{U}_{10}$ & $\begin{array}{l}\text { 3D } \\
\text { Coordination }\end{array}$ & $\begin{array}{l}\text { A process in which } 3 \mathrm{D} \text { coordination software is used to } \\
\text { identify } 3 \mathrm{D} \text { geometric conflicts by comparing } 3 \mathrm{D} \text { models of } \\
\text { building systems. }\end{array}$ \\
\hline
\end{tabular}

\section{Research method}

\section{Overall Approach}

To achieve the objective of this work, the research was organized into three stages, displayed in Figure 1, in the following way: (1) explanation of assessment instruments to measure the level of implementation of BIM uses and the lean design management (LDM) practices; (2) characterization of the sample of projects and data collection strategy; and (3) data exploration, including reliability analysis, descriptive statistics, association analysis using the Pearson chi-square test, and causal analysis using necessity and sufficiency relationships between both elements through a fuzzy set analysis. 


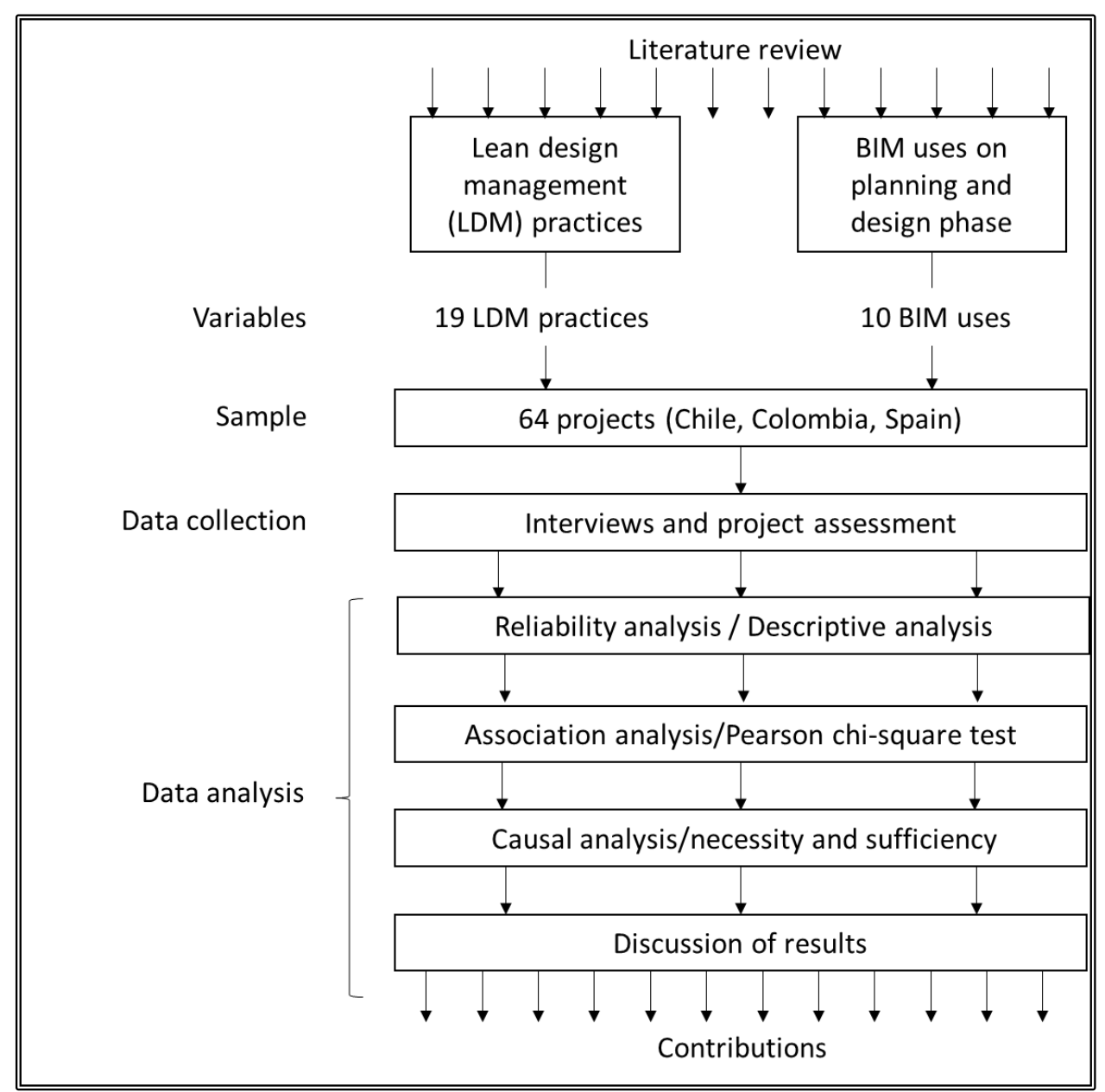

Figure 1: Research method

\section{$\underline{\text { Explanation of LDM Practices and BIM Uses instruments }}$}

In the first stage, a literature review was conducted to identify the Lean design management (LDM) practices and BIM uses in the planning and design phases of the infrastructure lifecycle. This is based on previous work of the research team, who identified LDM practices and BIM uses in two previous papers (Herrera et al. 2020; Rojas et al. 2019). The study by Herrera et al. (2020) was selected because it brings together several Lean design management practices applied in real projects in a single document. In addition, this study offers a questionnaire that allows the evaluation of the level of application of each practice on a scale of 1 to 5 . On the other hand, the study by Rojas et al. (2019) was selected, since it allows the evaluation of the gradualness of application of 10 BIM uses proposed by the Penn state guide on a scale of 1 to 5 . These two previous 
contributions aimed to identify the level of application of LDM practices and BIM uses in construction through assessment instruments.

The implementation of the LDM practices and BUA instruments was done in the following way. In each project, two semi-structured interviews were conducted. In the first interview, LDM practices were assessed, whereas in the second interview, BIM uses were assessed. The duration of each interview was from 40 to 60 minutes. The interviewer was the main researcher of the study, who also participated in the creation of both instruments. The interviewees were people with extensive knowledge of the projects assessed (project manager, BIM manager, and client representative), and more than 15 years of expertise in the field; the interviewees had the authorization of their superior to provide information as well as documents supporting this information. For each interview the procedure was as follows: First, the researchers conducted a recorded interview (audio was recorded with the consent of the interviewee), with the project manager and the BIM manager, considering all the points addressed in the questionnaires. Then, to maintain objectivity, two researchers (also co-authors of this paper) listened to the recorded interviews and individually rated each project according to each of the management practices that were defined in the questionnaire, using the 5-point Likert scale explained below. Rojas et al. (2019) introduced the BUA questionnaire, and Herrera et al. (2020) presented the LDM practices questionnaire. Then, in a collaborative session, the two researchers who revised the in the interviews were asked to discuss the final qualification of each practice. Finally, to maintain the objectivity of the ratings, a concordance analysis of the evaluations of the two researchers was conducted using the Kappa Cohen test to measure the level of concordance.

The LDM practices questionnaire has five levels for the 19 practices. Each LDM practice follows the method of Bloom and Van Reenen (2010), i.e., there is a description 
for scores 1, 3 and 5, while scores 2 and 4 are defined as intermediate points between 13 and 3-5, respectively. The score descriptions are (1) a traditional management practice, (3) an initial lean design management practice, and (5) a developed lean design management practice (Herrera et al. 2020). The BUA questionnaire qualifies each use on a scale from one to five, where the minimum level (1) means that there is no use of the BIM model and the maximum level (5) means that the organization uses it in a way that realizes all its applications. The proposal of classification by levels allows having a structured and consistent instrument. Table 3 presents a general description for each level (Rojas et al. 2019).

Table 3: BIM levels-a general description for each level

\begin{tabular}{|c|c|}
\hline Level & General description \\
\hline 1 & Traditional methods (2D model). \\
\hline 2 & Low use of BIM and little information in the model. \\
\hline 3 & Medium use of BIM and sufficient information for BIM. \\
\hline 4 & High use of BIM. \\
\hline 5 & Full use of BIM. The best tools are utilized to realize all its applications. \\
\hline
\end{tabular}

\section{$\underline{\text { Sample and Data Collection }}$}

In the second stage, the researchers invited all the companies collaborating with the Production Management Centre (GEPUC) in Santiago (Chile) to join in research; 64 projects of companies interested were assessed, which had the following characteristics: (1) the contracting system was design-bid-build; (2) BIM methodology was being used; and (3) the project manager and/or BIM manager agreed to provide actual project information. The infrastructure projects used in this research were hospitals and airports; thus, it was possible to compare BIM uses between building and infrastructure projects. The assessment of the 64 construction projects was carried out using the LDM practices instrument (Herrera et al. 2020) and the BUA instrument (Rojas et al. 2019).

Table 1: Summary of project characteristics 


\begin{tabular}{|c|c|c|c|}
\hline Country & Building project & Infrastructure project & Total \\
\hline Colombia & 12 & 2 & 14 \\
\hline Chile & 20 & 12 & 32 \\
\hline Spain & 12 & 6 & 18 \\
\hline Total & $\mathbf{4 4}$ & $\mathbf{2 0}$ & $\mathbf{6 4}$ \\
\hline
\end{tabular}

\section{$\underline{\text { Data Analysis }}$}

In the third stage, the authors performed a descriptive analysis from the data of the 64 projects. First, to measure whether the scale of the BUA questionnaire and the LDM practices questionnaire consistently reflect the construct it is measuring, a reliability analysis of the two instruments was carried out using Cronbach's alpha test. Second, to understand the level of application of LDM practices and BIM uses of the sample of the 64 projects, the authors performed a frequency and percentile analysis for each LDM practice and BIM use. Third, to understand the relationship between LDM practices and BIM uses, the researchers performed an association analysis using Pearson's chi-square test. Finally, to understand the causality between LDM practices and BIM uses, a necessity and sufficiency analysis between both elements was performed using a fuzzy set analysis. A necessity and sufficiency analysis allows evaluating the degree of consistency of the causal relationship between two variables (Rihoux and Ragin 2009).

For the association analysis, the authors built 19x10 (190) contingency tables between each LDM practice and each BIM use. The researchers decided to apply the original scale of five levels for LDM practices, while for the BIM uses, they defined a binary scale, i.e., (0) when the project did not apply the BIM use (levels 1 and 2 in the original scale) and (1) when the project applied the BIM use (levels 3 to 5 in the original scale). Therefore, each contingency table had 5 columns and 2 rows. Then, the authors defined the hypothesis test: $\left(\mathrm{H}_{0}\right)$ there is no association between the LDM practice (n) and the BIM use $\mathrm{U}(\mathrm{m})$; and $\left(\mathrm{H}_{1}\right)$ there is an association between the LDM practice (n) and the BIM use U (m). Finally, the researchers performed Person's chi-square test for each 
contingency table with a level of significance of $5 \%$; a degree of freedom (df) $d f=(r-1)$ $(c-1)$, where $\mathrm{r}$ is the number of rows (2) and $\mathrm{c}$ is the number of columns (5); therefore, the degree of freedom for each test was four.

The chi-square was calculated for each contingency table (190 in total) using the following procedure. Each contingency table had an observed value $(\mathrm{O})$. Then, the researchers calculated the expected frequency $(E)$, which represents the expected value of the two variables that are independent of one another. Later, the authors calculated each chi-square according to Equation 1.

$$
\chi^{2}=\sum \frac{\left(O_{i}-E_{i}\right)^{2}}{E_{i}}(\mathrm{Eq}, 1)
$$

Given the degree of freedom $(\mathrm{df}=4)$ and each chi-square statistic value, the level of significance ( $p$-value) can be found with the chi-square distribution. If the p-value $<0.05$, then the null hypothesis can be rejected. Therefore, there is a relationship between the LDM practice (n) and the BIM use $\mathrm{U}(\mathrm{m})$. If the $\mathrm{p}$-value $>0.05$, then the null hypothesis cannot be rejected. Therefore, there is not a relationship between the LDM practice (n) and the BIM use $\mathrm{U}(\mathrm{m})$.

If the correlation exists, then the level of association with the contingency coefficient standardized (C stand) has to be computed as indicated in Equation 2, where " $\mathrm{N}$ " is the size of the sample (64 projects) and " $\mathrm{k}$ " is the minimum between the numbers of rows and columns (2). Then, the level of association can be defined using Table 5 (Akoglu 2018).

$$
C_{\text {stand }}=\sqrt{\frac{\chi^{2} \cdot k}{\left(\chi^{2}+N\right) \cdot(k-1)}}(\text { Eq. } 2)
$$

Table 2: Level of association according to the standardized contingency coefficient

\begin{tabular}{|l|l|}
\hline C stand & Level of association \\
\hline+0.70 or higher & Very strong relationship \\
\hline 0.40 to 0.69 & Strong relationship \\
\hline 0.30 to 0.39 & Moderate relationship \\
\hline 0.20 to 0.29 & Weak relationship \\
\hline
\end{tabular}




\begin{tabular}{|l|l|}
\hline 0.01 to 0.19 & No or negligible relationship \\
\hline 0.00 & No relationship \\
\hline
\end{tabular}

Therefore, to understand the application of the association analysis between an LDM practice and a BIM use, two hypothetical cases are presented below in Figure 2. This figure shows first (a) when an LDM practice and a BIM use are totally independent, i.e., there is no association between BIM use and LDM practice. This is reflected with a chisquare and a standardized contingency coefficient equal to 0.00 ; in other words, the use of BIM in a project may or may not perform the lean management practice with the same probability. Figure, in (b), shows an LDM practice and a BIM use with a high association. In this case, there is a very strong relationship between the existence of the BIM use and the LDM practice. This is reflected by a chi-square of 37.25 ( $p$-value $<0.05$ ) and a standardized contingency coefficient equal to 0.85 , i.e.; if BIM is used in a project, there is also a high probability that lean management practice is being applied in the design phase.

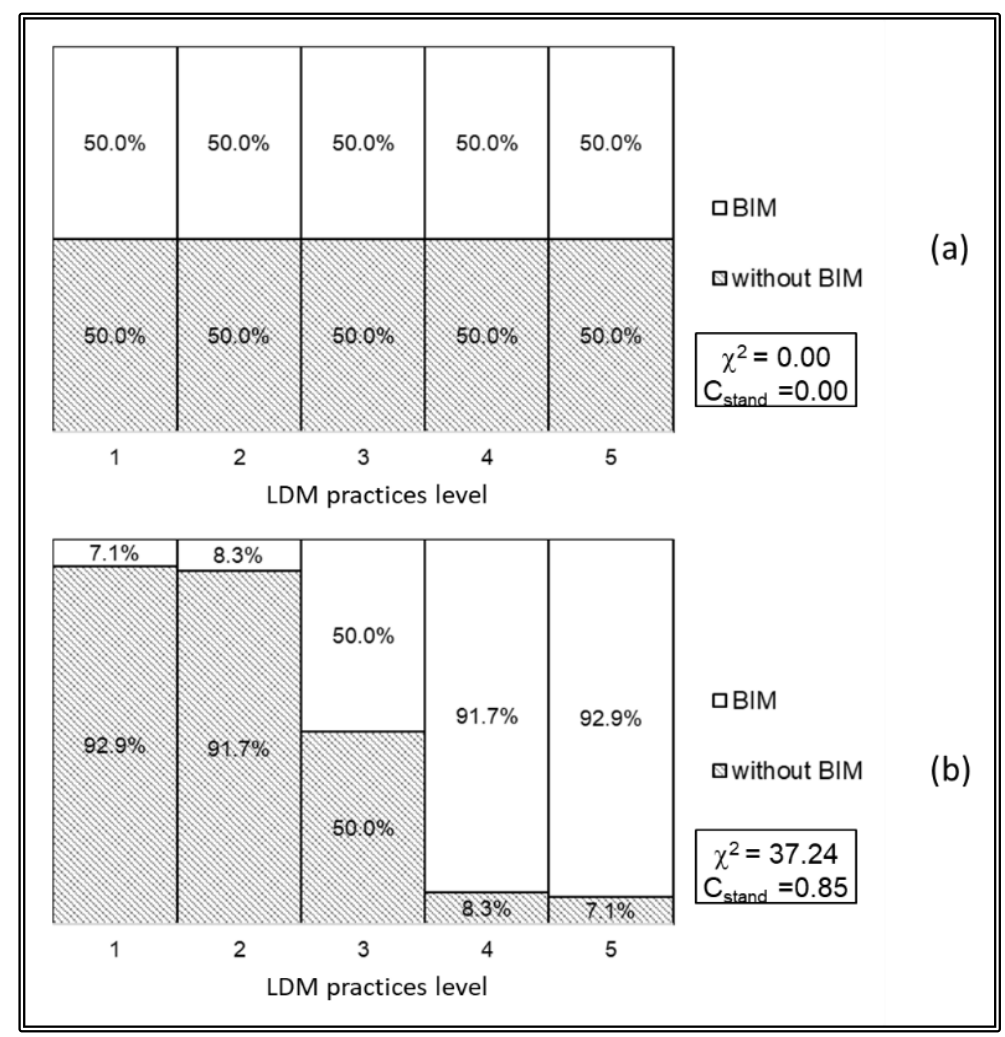


Figure 2: Association analysis in two hypothetical cases

Finally, to understand the causality between LDM practices and BIM uses, a necessity and sufficiency analysis between both elements was performed using a fuzzy set analysis. For this analysis, two variables were defined: (1) the proportion between the number of LDM practices with an initial or higher lean application (score three or higher) and the total of 19 LDM practices, and (2) the proportion between the number of BIM uses with an initial or higher BIM application (score three or higher) and the total of 10 BIM uses. The LDM practices proportion $\left(p_{l}\right)$ and the BIM uses proportion $\left(p_{b}\right)$ have a range between 0 and 1.

Then, the causal relationship between $p_{l}$ and $p_{b}$ was defined through an analysis of necessity and sufficiency. A condition is necessary if it is present every time the outcome of interest occurs (although in some cases where the condition is present, the outcome of interest does not occur). On the other hand, a condition is sufficient if the outcome of interest is present whenever the condition is present (although it may also be present in the absence of the condition) (Rihoux and Ragin 2009).

With fuzzy sets, the consistency of the necessary condition relationship depends on the degree to which it can be shown that membership in the outcome is consistently less than or equal to memberships in this cause (Outcome $_{\mathrm{i}} \leq$ Condition $_{\mathrm{i}}$ ). This inequality is the reverse of the inequality defining the consistency of the sufficient condition relationships (Outcome ${ }_{i} \geq$ Condition $_{i}$ ) (Ragin 2006). In this case, researchers assessed the necessity and sufficiency relationship between the LDM practices proportion $\left(p_{l}\right)$ and the BIM uses proportion $\left(p_{b}\right)$ through the consistency score. A perfect consistency score will take a value of 1.0; however, when there are more than 20 cases (projects), a consistency score of 0.75 or higher has a strong causal relationship (Schneider and Wagemann 2012). 


\section{Results and discussion}

From the 64 evaluated projects, the authors analyzed the internal consistency of the LDM practices and the BUA instruments using Cronbach's alpha coefficient. For the LDM practices instrument, which has 19 items, the researchers calculated a Cronbach's alpha coefficient of 0.918 ; hence, the LDM practices have a high reliability. In the same way, for the BUA instrument, which has 10 items, the authors obtained a Cronbach's alpha coefficient of 0.867 , i.e., a high reliability. Therefore, both instruments present a high level of internal consistency. In addition, Cohen's kappa values are 0.81 and 0.92 in the LDM practices questionnaire and BUA instrument, respectively. Therefore, the consistency between the assessment between the two evaluators indicated a high degree of agreement on both instruments.

The LDM practices with the highest level of implementation are $\mathrm{SM}_{3}$ "requirements management (identification of constraints, technical specifications and special requirements)" and $\mathrm{SM}_{4}$ "client systematic participation and support during meetings concerning decision making and resolution of problems"; they are the only LDM practices where a higher level than the initial LDM practices implementation exists. Both LDM practices belong to the stakeholder management category, this category being one of the most important in any kind of project (Mok et al. 2015; Molwus et al. 2017). This result is good news for design projects, since requirements management is usually one of the critical elements in construction project management (Molwus et al. 2017). 


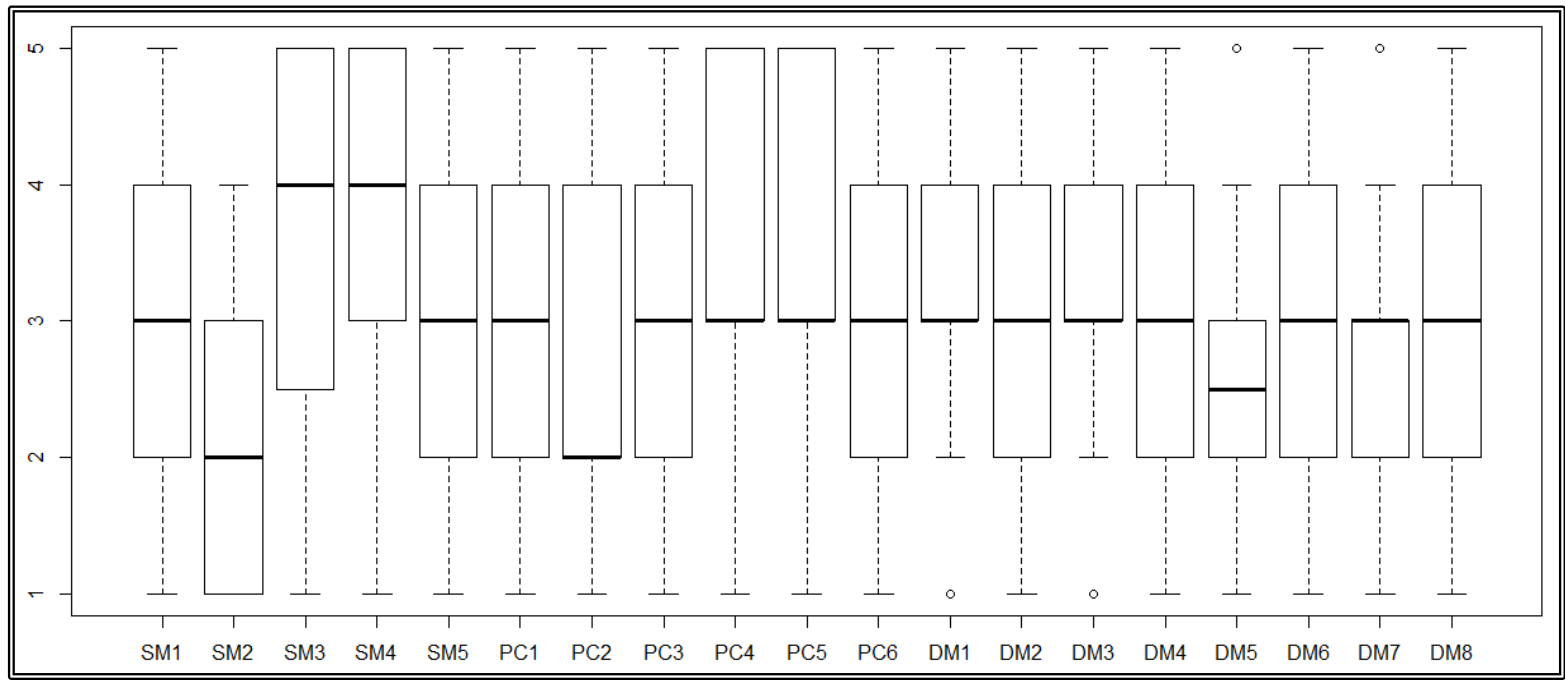

Figure 3: LDM practices assessment (Herrera et al. 2020)

In addition, $75 \%$ of the projects are beginning to apply lean with the practices $\mathrm{PC}_{4}$ "planning in different levels" and $\mathrm{PC}_{5}$ "constrains management visualization", even at initial levels. The same happens with the LDM practices $\mathrm{DM}_{1}$ "collaborative solving problems" and $\mathrm{DM}_{3}$ "PDCA problem solving". The academy has focused on the process, collaboration and planning of the design phase to reduce waste in this phase of the construction project (Munthe-kaas et al. 2015). Thus, the implementation of these LDM practices implies that there has been an increase in awareness around excellent processes and planning.

On the other hand, the LDM practices with the lowest level of implementation are $\mathrm{SM}_{2}$ "builders in early stages", $\mathrm{DM}_{5}$ "decision-making until the last responsible moment", and $\mathrm{DM}_{7}$ "multicriteria decision-making", where lean implementation levels are practically nonexistent in approximately $75 \%$ of the evaluated projects. The early involvement of builders in the design phase represents the best opportunities for a successful project (Reifi and Emmitt 2013); however, it is difficult to implement LDM practices in a project with a design-bid-build delivery system (Mesa et al. 2016), as shown in the 64 projects that were evaluated in this study. On the other hand, LDM practices associated with the decision-making process are increasingly being implemented in Lean 
projects; choosing by advantages (CBA) is the most commonly used technique in those projects (Arroyo et al. 2016). Additionally, there are high ranges of variability, since in most LDM practices (15 of 19), there is a two-level difference between the 75 th percentile and the 25 th percentile. This variability reflects that lean design practices are not yet a standard in management at this stage of the project.

The BIM uses with the highest level of implementation are $\mathrm{U}_{5}$ "design review", $\mathrm{U}_{9}$ "design authoring", and $\mathrm{U}_{10}$ "3D coordination". 3D coordination is limited to visualization and clash detection (Shafiq et al. 2013); however, there are many possibilities for coordination to be missed in this process, especially with specialists with different disciplines who often do not think about the other disciplines' responsibilities (Liu et al. 2017). Design authoring is a process in which software is used to develop a building information model, and the project is designed in a BIM model, where the typical iterations of a project are made, and everything is built directly in the BIM software (Kreider 2013; Rojas et al. 2019). A design review between different specialists is essential for BIM to become a collaborative methodology that facilitates decision making and improves the design process (Liu et al. 2017). Thus, the high level of execution of these BIM uses is aligned with the first BIM implementation efforts in the AEC industry (Gu and London 2010).

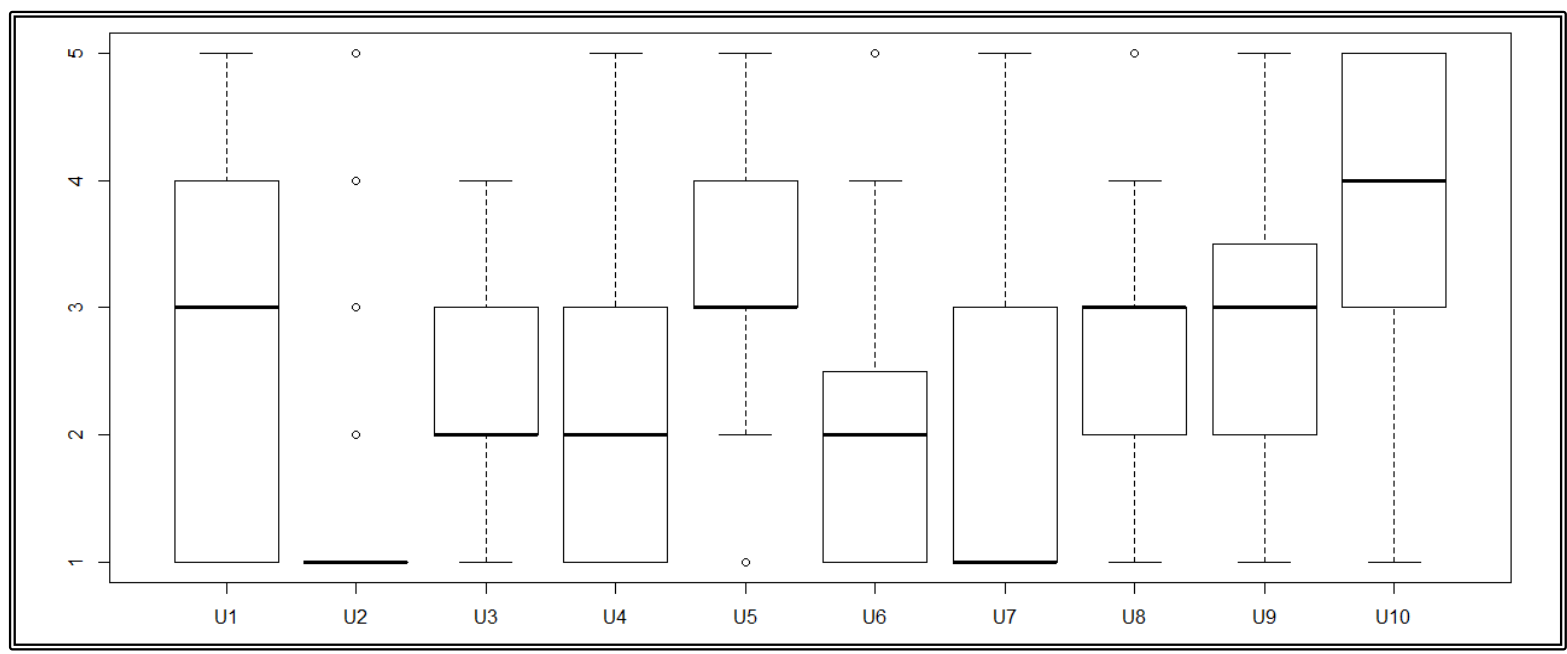


Figure 4: BIM uses assessment

The BIM uses with a medium level of implementation are $\mathrm{U}_{1}$ "cost estimation", $\mathrm{U}_{3}$ "site analysis", $\mathrm{U}_{4}$ "space planning", and $\mathrm{U}_{8}$ "engineering analysis". The estimation of quantities and subsequent estimation of the project budget is a basic activity that is carried out in all types of projects with or without BIM (Porwal and Hewage 2013); however, the use of BIM allows the project budget to be estimated more quickly and accurately (Rojas et al. 2019). This and other activities in the planning phase of the construction project are beginning to be implemented in their early stages, as are the LDM practices associated with planning and analysis.

On the other hand, the BIM uses with the lowest level of implementation are $\mathrm{U}_{2}$ "4D planning", $\mathrm{U}_{6}$ "code validation", and $\mathrm{U}_{7}$ "sustainability analysis". 4D planning, also known as 4D modeling, is one of the least used applications, which is consistent with a study that indicates this use as important but under a baseline of 74 other key factors of BIM implementation (Tsai et al. 2014). In the case of sustainability analysis and code validation, in the countries that were studied, it is still difficult to ask external designers to develop the whole process on a BIM platform (Rojas et al. 2019).

Then, a Pearson's chi-square test of independence was performed to examine relationships between BIM uses and the LDM practices of the 64 projects. The main results are summarized in Table 6 . The chi-square test showed no significant association between the BIM use $\mathrm{U}_{8}$ "engineering analysis" and any LDM practices ( $\mathrm{p}$-values $>0.05$ ). This means that engineering analysis is being used as a technique. However, there are no structured management practices that allow these agents to be actively involved in planning and decision making in the engineering process. Therefore, it is essential that in schools of design and engineering, students be trained to explore state-of-the-art 
computer-supported collaborative devices and to collaborate across disciplines (Gu and London 2010).

Table 6: Pearson's chi-square test: related variables

\begin{tabular}{|c|c|c|c|}
\hline Var & $\chi \mathbf{2}$ & p-value & Coef. Cont. Stand. \\
\hline $\mathrm{U}_{1}-\mathrm{SM}_{1}$ & 13.135 & 0.011 & 0.5840 \\
\hline $\mathrm{U}_{1}-\mathrm{PC}_{4}$ & 10.033 & 0.040 & 0.5200 \\
\hline $\mathrm{U}_{1}-\mathrm{DM}_{1}$ & 14.756 & 0.005 & 0.6124 \\
\hline $\mathrm{U}_{2}-\mathrm{PC}_{4}$ & 11.298 & 0.023 & 0.5473 \\
\hline $\mathrm{U}_{3}-\mathrm{PC}_{2}$ & 11.375 & 0.023 & 0.5487 \\
\hline $\mathrm{U}_{3}-\mathrm{PC}_{6}$ & 12.105 & 0.017 & 0.5643 \\
\hline $\mathrm{U}_{3}-\mathrm{DM}_{4}$ & 9.486 & 0.050 & 0.5077 \\
\hline $\mathrm{U}_{4}-\mathrm{SM}_{4}$ & 10.590 & 0.032 & 0.5332 \\
\hline $\mathrm{U}_{4}-\mathrm{PC}_{1}$ & 9.603 & 0.048 & 0.5105 \\
\hline $\mathrm{U}_{4}-\mathrm{PC}_{3}$ & 10.815 & 0.029 & 0.5374 \\
\hline $\mathrm{U}_{4}-\mathrm{PC}_{4}$ & 15.694 & 0.003 & 0.6279 \\
\hline $\mathrm{U}_{4}-\mathrm{PC}_{5}$ & 14.378 & 0.006 & 0.6053 \\
\hline $\mathrm{U}_{4}-\mathrm{PC}_{6}$ & 13.117 & 0.011 & 0.5827 \\
\hline $\mathrm{U}_{4}-\mathrm{DM}_{1}$ & 10.677 & 0.030 & 0.5346 \\
\hline $\mathrm{U}_{4}-\mathrm{DM}_{2}$ & 9.849 & 0.043 & 0.5162 \\
\hline $\mathrm{U}_{4}-\mathrm{DM}_{6}$ & 13.320 & 0.010 & 0.5869 \\
\hline $\mathrm{U}_{4}-\mathrm{DM}_{8}$ & 14.261 & 0.007 & 0.6039 \\
\hline $\mathrm{U}_{5}-\mathrm{SM}_{4}$ & 10.722 & 0.040 & 0.5360 \\
\hline $\mathrm{U}_{5}-\mathrm{SM}_{5}$ & 10.972 & 0.027 & 0.5416 \\
\hline $\mathrm{U}_{5}-\mathrm{DM}_{2}$ & 13.915 & 0.008 & 0.5982 \\
\hline $\mathrm{U}_{6}-\mathrm{SM}_{2}$ & 15.291 & 0.002 & 0.6208 \\
\hline $\mathrm{U}_{6}-\mathrm{SM}_{5}$ & 9.680 & 0.046 & 0.5119 \\
\hline $\mathrm{U}_{6}-\mathrm{PC}_{1}$ & 20.868 & 0.000 & 0.7014 \\
\hline $\mathrm{U}_{6}-\mathrm{PC}_{2}$ & 11.994 & 0.017 & 0.5614 \\
\hline $\mathrm{U}_{6}-\mathrm{PC}_{3}$ & 17.103 & 0.002 & 0.6491 \\
\hline $\mathrm{U}_{6}-\mathrm{PC}_{4}$ & 13.797 & 0.008 & 0.5954 \\
\hline $\mathrm{U}_{6}-\mathrm{DM}_{6}$ & 11.964 & 0.018 & 0.5614 \\
\hline $\mathrm{U}_{7}-\mathrm{SM}_{5}$ & 27.676 & 0.000 & 0.7764 \\
\hline $\mathrm{U}_{7}-\mathrm{PC}_{2}$ & 11.423 & 0.022 & 0.5501 \\
\hline $\mathrm{U}_{9}-\mathrm{PC}_{4}$ & 10.130 & 0.038 & 0.5233 \\
\hline $\mathrm{U}_{9}-\mathrm{DM}_{1}$ & 10.461 & 0.033 & 0.5303 \\
\hline $\mathrm{U}_{10}-\mathrm{DM}_{1}$ & 15.112 & 0.004 & 0.6180 \\
\hline $\mathrm{U}_{10}-\mathrm{DM}_{2}$ & 10.983 & 0.027 & 0.5416 \\
\hline & & & \\
\hline
\end{tabular}

In addition, the chi-square test showed no significant association between any BIM use and the $\mathrm{LDM}$ practices: $\mathrm{SM}_{3}$ "requirements management (identification of constraints, technical specifications and special requirements)", $\mathrm{DM}_{3}$ "PDCA problem solving", $\mathrm{DM}_{5}$ "decision-making until the last responsible moment", and $\mathrm{DM}_{7}$ 
"multicriteria decision-making". The accurate requirements definition is a key factor in any construction project (Molwus et al. 2017). Therefore, the independence of this variable with or without the use of BIM demonstrates that the AEC industry has considered this a basic factor for the development of projects. Similarly, problem solving using PDCA is a widely used technique. In this study, 75\% of projects apply these LDM practices at level 3 or higher; thus, its application is independent of the use of BIM. However, there is evidence of the joint application of PDCA and BIM in the context of the Digital Obeya Room, which promotes activities that use BIM-Lean approaches aiming at continuous flow and Jidoka (Nascimento et al. 2018). The practices associated with decision making $\left(\mathrm{DM}_{5}\right.$ and $\left.\mathrm{DM}_{7}\right)$ are not related to any use of BIM, since both LDM practices have a low level of application, it is not possible to make strong conclusions about this relationship; however, it can be summarized that applying certain uses of BIM by themselves does not imply that any LDM practice aligned with decision making is being carried out.

Table 6 shows the chi-square test results for the pair of variables that are related. In addition, this table presents the calculated chi-square, the associated p-value and the standardized contingent coefficient of each pair of variables. The 33 relationships found have a standardized contingent coefficient between 0.50 and 0.63 , i.e., the associativity between all pairs of variables has a strong relationship, as shown in Table 5.

The 33 significant relationships presented in Table 6 are equivalent to $17.36 \%$ of the potential relationships between the 19 LDM practices and the 10 BIM uses. There are four LDM practices and one use of BIM that are not present in any relationship, so the relationship between the fifteen LDM practices and the nine uses of BIM can be visualized in Fig. 5. In this figure, a graph can be visualized where the nodes are the variables LDM practices and BIM uses in white and black, respectively; the size of the 
nodes is equivalent to the number of links that this variable has. The link between variables is represented with a line that indicates a weight equivalent to the standardized contingency coefficient. Then, through an attraction and repulsion algorithm between the nodes called Force Atlas (Thangaraj and Amutha 2018), the variables with the highest relative relationship are grouped.

From the graph, it can be observed that $\mathrm{U}_{4}$ "space programming" and $\mathrm{U}_{6}$ "code validation" are the BIM uses that are most related to LDM practices. On the other hand, the LDM practices associated with more BIM uses are $\mathrm{PC}_{4}$ "gradual planning", $\mathrm{PC}_{1}$ "use of database for planning", $\mathrm{DM}_{1}$ "collaborative problem solving" and $\mathrm{DM}_{2}$ "causal analysis of problems". Each LDM practice is connected on average to two or three BIM uses, and through a clustering analysis, five groupings can be identified that include one or two BIM uses. Ten years ago, Sacks et al. (2010) proposed a framework with 56 potential interactions between BIM functionalities and Lean Construction principles, where they argued that at that time, companies and professionals were still in the process of learning BIM and Lean. Currently, the actual interaction between Lean and BIM is still low in the planning and design phase of construction projects in relation to the potential interactions between Lean and BIM. 


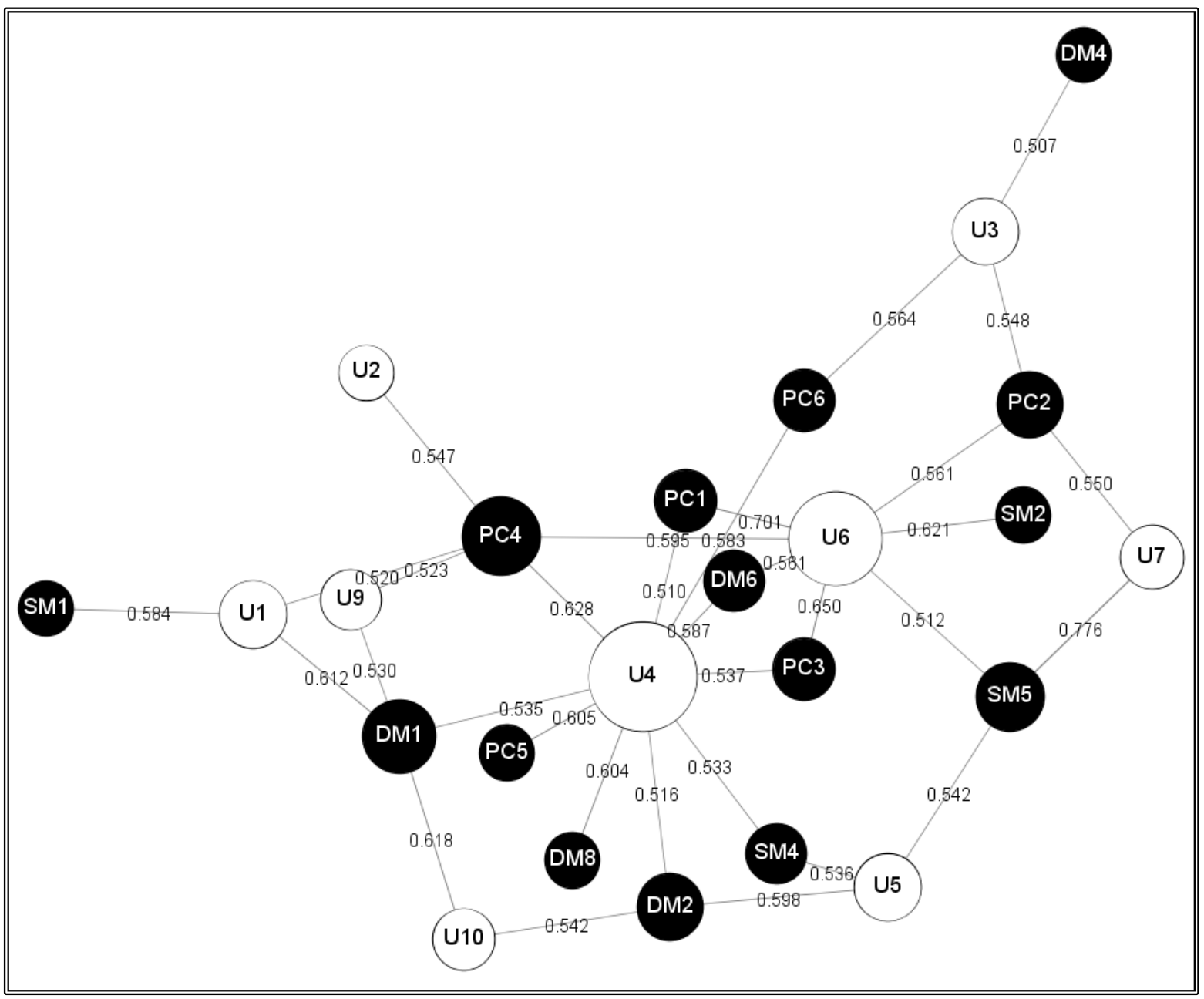

Figure 5: Association between LDM practices and BIM uses

Finally, a necessity and sufficiency analysis was performed to assess the causal relationship between the LDM practices proportion ( $\mathrm{pl}$ ) and the BIM uses proportion $(\mathrm{pb})$ using the data of the 64 evaluated projects. Figure 6 shows on the x-axis the BIM use proportion of each project, and on the y-axis the corresponding LDM practices proportion of that project. The graph shows a higher density of points in the upper-left triangle, which means that more projects have a higher proportion of LDM practices than the proportion of BIM uses; i.e., a higher proportion of BIM uses is a sufficient condition to result in a higher proportion of LDM practices. 


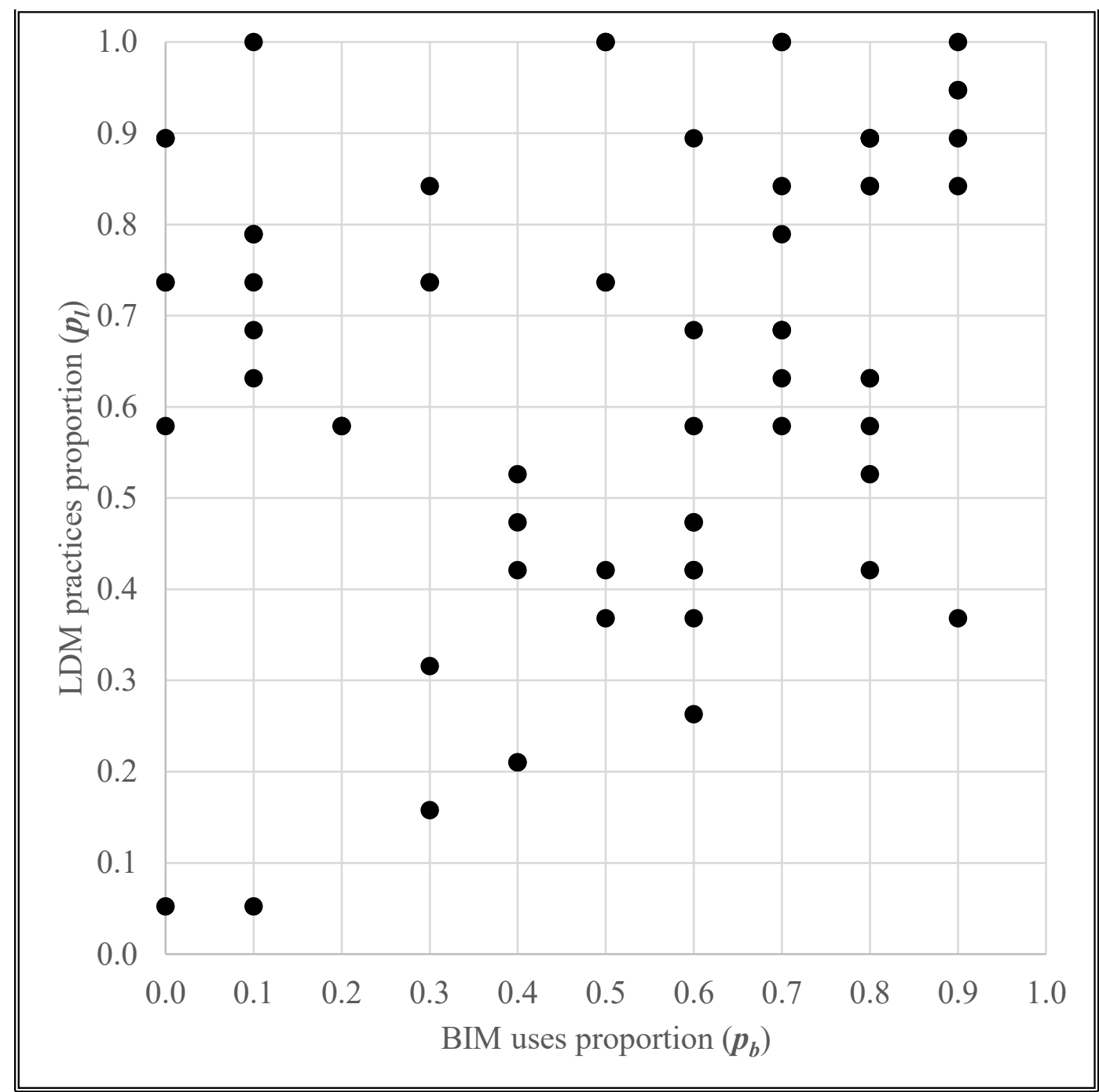

Figure 1: LDM practices proportion and BIM uses proportion graph.

To confirm the graphical interpretation of Figure 1, it is necessary to calculate the consistency score of the relationship between the two variables. Table 7 presents the consistency index for the necessity and sufficiency relationship between the LDM practices proportion $\left(\boldsymbol{p}_{\boldsymbol{l}}\right)$ and the BIM uses proportion $\left(\boldsymbol{p}_{\boldsymbol{b}}\right)$. From the consistency analysis, it can be interpreted that a higher LDM practices proportion is a necessary condition to have a higher BIM use proportion as a result. In contrast, a higher proportion of BIM uses is a sufficient condition to have a higher proportion of LDM practices as a result. That is, whenever a project performs a high proportion of BIM uses, this implies that a high proportion of LDM practices is being applied; however, a high proportion of LDM practices does not ensure that a high proportion of BIM uses is being applied. In other 
words, when an organization develops more BIM uses in its projects, teams tend to adopt more lean practices to manage the project.

Table 3: Consistency Score between $\mathrm{p}_{\mathrm{b}}$ and $\mathrm{p}_{\mathrm{l}}$

\begin{tabular}{|c|c|c|c|}
\hline Condition & Outcome & Necessity & Sufficiency \\
\hline$p_{l}$ & $p_{b}$ & 0.8738 & 0.6733 \\
\hline$p_{b}$ & $p_{l}$ & 0.6733 & 0.8748 \\
\hline
\end{tabular}

\section{Conclusions}

This study examined the association among BIM uses and lean design management practices in the planning and design of construction projects through the BUA instrument and the LDM practices questionnaire, respectively. Based on data from 64 projects, this study performed an association analysis between each pair of variables, i.e., 10 BIM uses and 19 LDM practices. A chi-square analysis revealed 33 significant relationships between BIM uses and lean design management practices, which is equivalent to $17.36 \%$ of the potential relationships between the variables measured with these instruments. The associations found have a standardized contingent coefficient between 0.50 and 0.63 ; i.e., the associativity between all pairs of variables has a strong relationship. No association was found between the use of BIM $\mathrm{U}_{8}$ "engineering analysis" and any LDM practices. There was also no association between $\mathrm{SM}_{3}$ (requirements management) and $\mathrm{SM}_{4}$ (client systematic participation) practices with any of the ten BIM uses. On the other hand, the BIM uses $\mathrm{U}_{4}$ "space programming" and $\mathrm{U}_{6}$ "code validation" were the BIM uses that are most related to LDM practices. In addition, the LDM practices associated with more BIM uses were $\mathrm{PC}_{4}$ "gradual planning", $\mathrm{PC}_{1}$ "use of database for planning", $\mathrm{DM}_{1}$ "collaborative problem solving", and $\mathrm{DM}_{2}$ "causal analysis of problems". The analysis of the relationship between LDM practices and BIM uses allows having empirical evidence of the LDM practices that are present in each BIM use in the design phase of construction 
projects. LDM practices from the categories "planning and control" and "problem solving and decision making" are more related to BIM uses than LDM practices from the category "stakeholder management". Additionally, it can be concluded that if a project applies a higher proportion of BIM uses, it will tend to apply a higher proportion of LDM practices; however, this relationship is not as clear in the other way around.

The results confirm that the implementation of BIM uses and LDM practices, at the design phase, are at a nascent stage, given that the relationship between Lean and BIM and their potential have not been explored extensively. In this learning phase, BIM uses are still applied as isolated technological implementations of collaborative management and other best management practices aligned with Lean. Therefore, this study reinforces the need to apply BIM as a whole to LDM, and even more at the design and planning phases of the infrastructure lifecycle. Additionally, it is concluded that there is no double implication between BIM uses and the application of LDM, since with the causal analysis, it was found that the application of BIM uses implies a greater application of LDM practices; however, a greater application of such practices does not imply a greater application of BIM uses. This means that organizations that are more advanced in the development of BIM in their projects tend to apply design management practices aligned with lean, which encourages collaboration, transparency of information and better planning, problem solving and decision making in the design of the construction project.

Moreover, since several countries are defining a regulatory framework that promotes the use of BIM, organizations that manage their projects under Lean principles will naturally be able to apply the BIM methodology. The results obtained allow project managers and executives to carry out a benchmark study of the practices and uses of BIM applied in their projects in comparison with other projects in the planning design phase. Additionally, it allows the identification of sets of design management practices 
associated with certain BIM uses, allowing the adopter of these methodologies to prioritize efforts in the combined implementation of Lean and BIM in their projects.

Some limitations of this study are stated next. The 64 projects evaluated are not a statistical sample, considering the number of projects in the design process in the countries where they were evaluated; hence, a larger number of projects should be assessed. The qualification of each project has to be done with at least two researchers or specialized consultants to provide higher objectivity of the assessment; therefore, future studies could create a instrument that would be used as a self-evaluation for each project. In addition, this study did not measure the effect of the application of LDM practices and BIM uses on the performance of the 64 projects. Therefore, future research should aim to assess the performance of the design process and the organizational performance of the design team; in this way, it will be possible to identify the effect of LDM practices on the performance of the construction project, both during its design and in its execution. In addition, this study did not include particular tools, such as, set-based design, target value design, the last planner system, choosing by advantages, or big room, among others. Within these tools one or more of the LDM practices are applied; therefore, it would be interesting to study the impact of the application of BIM with one of them in the design phases of construction projects.

\section{References}

AIA. (2007). Integrated Project Delivery: A Guide. The American Institute of Architects, California.

Akoglu, H. (2018). “User's guide to correlation coefficientes.” Turkish Journal of Emergency Medicine, 18(3), 91-93.

Arayici, Y., Coates, P., Koskela, L., Kagioglou, M., Usher, C., and O’Reilly, K. (2011). "Technology Adoption in the BIM Implementation for Lean Architectural 
Practice.” Automation in Construction, Elsevier B.V., 20(2), 189-195.

Arroyo, P., Fuenzalida, C., Albert, A., and Hallowell, M. R. (2016). "Collaborating in

Decision Making of Sustainable Building Design: An Experimental Study

Comparing CBA and WRC Methods.” Energy and Buildings, Elsevier B.V., 128, $132-142$.

Ballard, G. (2008). “The Lean Project Delivery System: An Update.” Lean Construction Journal, 1-19.

Bloom, N., and Van Reenen, J. (2007). "Measuring and Explaining Management Practices Across Firms and Countries.” Quarterly Journal of Economics, 122(4), $1341-1408$.

Bloom, N., and Van Reenen, J. (2010). "New Approaches to Surveying Organizations." American Economic Review, 100(2), 105-109.

Bloomberg, M. R., Burney, D. J., and Resnick, D. (2012). BIM Guidelines. New York. Building and Construction Authority. (2013). Singapore BIM Guide - V2.0. Cornet. Dave, B. A. (2013). "Developing a Construction Management System Based on Lean Construction and Building Information Modelling.” University of Salford.

Dave, B., Koskela, L., Kiviniemi, A., Owen, R., and Tzortzopoulos, P. (2013). Implementing Lean in construction. CIRIA, London.

Eastman, C. M., Teicholz, P., Sacks, R., and Liston, K. (2008). BIM Handbook: A Guide to Building Information Modeling for Owners, Managers, Designers, Engineers and Contractors. John Wiley \& Sons Ltd., New Jersey.

Eastman, C. M., Teicholz, P., Sacks, R., and Liston, K. (2011). BIM Handbook: A Guide to Building Information Modeling for Owners, Managers, Designers, Engineers and Contractors. John Wiley \& Sons Ltd., New Jersey.

Fakhimi, A. H., Majrouhi Sardroud, J., and Azhar, S. (2016). "How Can Lean, IPD and 
BIM Work Together?" 33rd International Symposium on Automation and Robotics in Construction (ISARC), ISARC, 1-8.

Forbes, L. H., and Ahmed, S. M. (2011). Modern Construction: Lean Project Delivery and Integrated Practices. Taylor \& Francis, New York.

Formoso, C. T., Tzotzopoulos, P., Jobim, M. S., and Liedtke, R. (1998). "Developing a Protocol for Managing the Design Process in the Building Industry.” 6th Annual Conference of the International Group for Lean Construction 1998, IGLC 1998, Guarujá.

Gambatese, J. A., Pestana, C., and Lee, H. W. (2017). “Alignment between Lean Principles and Practices and Worker Safety Behavior." Journal of Construction Engineering and Management, 143(1).

Gerber, D. J., Becerik-Gerber, B., and Kunz, A. (2010). "Building Information Modeling and Lean Construction: Technology, Methodology and Sdvances from Practices." 18th Annual Conference of the International Group for Lean Construction, International Group for Lean Construction, Haifa, Israel, 1-11. Gu, N., and London, K. (2010). “Automation in Construction Understanding and facilitating BIM adoption in the AEC industry." Automation in Construction, Elsevier B.V., 19(8), 988-999.

Harvard University Construction Management Council. (2010). BIM Uses Guide.

Al Hattab, M., and Hamzeh, F. (2015). "Using Social Network Theory and Simulation to Compare Traditional versus BIM-Lean Practice for Design Error Management.” Automation in Construction, Elsevier B.V., 52(4), 59-69.

Herrera, R. F., Mourgues, C., Alarcón, L. F., and Pellicer, E. (2020). “An Assessment of Lean Design Management Practices in Construction Projects.” Sustainability, 12(1), 1-19. 
Koskela, L. (2000). “An Exploration towards a Production Theory and its Application to Construction." Construction, 298.

Koskela, L., Ballard, G., and Tanhuanpää, V.-P. (1997). “Towards Lean Design Management." 5th Annual Conference of the International Group for Lean Construction 1997, IGLC 1997, Gold Coast, 1-13.

Kreider, R. (2013). “An Ontology of the Uses of Building Information Modeling.” Pennsylvania State University.

Kreider, R. G., and Messner, J. I. (2013). The Uses of BIM: Classifying and Selecting BIM Uses. The Pennsylvania State University, Pennsylvania.

Liu, Y., van Nederveen, S., Hertogh, M., Nederveen, S. Van, and Hertogh, M. (2017). "Understanding Effects of BIM on Collaborative Design and Construction : An Empirical Study in China.” International Journal of Project Management, Elsevier Ltd, APM and IPMA, 35(4), 686-698.

Magalingam, A., Yadav, A. K., and Varaprasad, J. (2015). "Investigating the Role of Lean Practices in Enabling BIM Adoption: Evidence from Two Indian Cases.” Journal of Construction Engineering and Management, 141(7).

Matta, G., Herrera, R. F., Baladrón, C., Giménez, Z., and Alarcón, L. F. (2018). “Using BIM-Based Sheets as a Visual Management Tool for On-site Instructions: A Case Study." IGLC 2018 - Proceedings of the 26th Annual Conference of the International Group for Lean Construction: Evolving Lean Construction Towards Mature Production Management Across Cultures and Frontiers, 1, 144-154.

Mesa, H. A., Molenaar, K. R., and Alarcón, L. F. (2016). "Exploring performance of the integrated project delivery process on complex building projects." International Journal of Project Management, Elsevier Ltd and Association for Project Management and the International Project Management Association, 34(7), 1089- 
1101.

Mok, K. Y., Shen, G. Q., and Yang, J. (2015). "Stakeholder Management Studies in Mega Construction Projects: A Review and Future Directions.” International Journal of Project Management, Elsevier Ltd, 33(2), 446-457.

Molwus, J. J., Erdogan, B., and Ogunlana, S. (2017). "Using Structural Equation Modelling (SEM) to Understand the Relationships Among Critical Success Factors (CSFs) for Stakeholder Management in Construction." Engineering, Construction and Architectural Management, 24(3), 426-450.

Munthe-kaas, T. S., Hjelmbrekke, H., and Lohne, J. (2015). "Lean Design versus Traditional Design Approach.” 23th Annual Conference of the International Group for Lean Construction 2015, IGLC 2015, International Group for Lean Construction, Perth, 578-588.

Nascimento, D., Caiado, R., Tortorella, G., Ivson, P., and Meiriño, M. (2018). “Digital Obeya Room: Exploring the Synergies between BIM and Lean for Visual Construction Management.” Innovative Infrastructure Solutions, Springer International Publishing, 3(19), 1-10.

O’Connor, R., and Swain, B. (2013). Implementing Lean in construction: Lean tools and techniques-an introduction. CIRIA, London.

Olatunji, O. A. (2011). "Modelling the costs of corporate implementation of building information modelling." Journal of Financial Management of Property and Construction, 16(3), 211-231.

Peralta, C. I. (2019). "BIM Maturity and its relationships with Lean and BIM uses performance.” Pontificia Universidad Católica de Chile.

Porwal, A., and Hewage, K. N. (2013). "Building Information Modeling (BIM) Partnering Framework for Public Construction Projects." Automation in 
Construction, Elsevier B.V., 31, 204-214.

Ragin, C. C. (2006). "Set Relations in Social Research: Evaluating their Consistency and Coverage." Political Analysis, 14(3), 291-310.

Reifi, M. H. El, and Emmitt, S. (2013). "Perceptions of Lean Design Management.” Architectural Engineering and Design Management, 9(3), 195-208.

Rihoux, B., and Ragin, C. C. (2009). "Introduction." Configurational Comparative Methods, SAGE Publications, California.

Rojas, M. J., Herrera, R. F., Mourgues, C., Ponz-Tienda, J. L., Alarcón, L. F., and Pellicer, E. (2019). "BIM Use Assessment (BUA) Tool for Characterizing the Application Levels of BIM Uses for the Planning and Design of Construction Projects." Advances in Civil Engineering, 2019, 1-9.

Sacks, R., Barak, R., Belaciano, B., and Gurevich, U. (2011). "Field Tests of the Kanbim ${ }^{\mathrm{TM}}$ Lean Production Management System.” 19th Annual Conference of the International Group for Lean Construction, International Group for Lean Construction, Lima, Perú, 1-12.

Sacks, R., Koskela, L., Dave, B. A., and Owen, R. (2010). “Interaction of Lean and Building Information Modeling in Construction." Journal of Construction Engineering \& Management, 136(9), 968-980.

Schimanski, C. P., Monizza, G. P., Marcher, C., and Matt, D. T. (2019). “Conceptual Foundations for a New Lean BIM-Based Production System in Construction.” 27th Annual Conference of the International Group for Lean Construction, International Group for Lean Construction, Dublin, Ireland, 877-888.

Schneider, C. Q., and Wagemann, C. (2012). Set-Theoric Methods for Social Sciences: A Guide to Qualitative Comparative Analysis. Cambridge University Press, Cambridge. 
Shafiq, M. T., Matthews, J., and Lockley, S. (2013). "A study of BIM collaboration requirements and available features in existing model collaboration systems." Journal of Information Technology in Construction, 18, 148-161.

Succar, B. (2016). 211in Model Uses List.

Succar, B., Sher, W., and Williams, A. (2012). "Measuring BIM Performance: Five Metrics." Architectural Engineering and Design Management, 8(2), 120-142.

Thangaraj, M., and Amutha, S. (2018). "Mgephi: Modified Gephi for Effective Social Network Analysis." International Journal of Scientific Research in Computer Science, Engineering and Information Technology, 3(1), 39-50.

Tsai, M., Mom, M., Hsieh, S., Tsai, M., and Hsieh, S. (2014). "Developing Critical Success Factors for the Sssessment of BIM Technology Adoption: Part I . Methodology and Survey." Journal of the Chinese Institute of Engineers, Taylor \& Francis, 37(7), 859-868. 